\title{
Nerve Growth Factor Infusion into the Denervated Adult Rat Hippocampal Formation Promotes Its Cholinergic Reinnervation
}

\author{
Theo Hagg, H. Lee Vahlsing, Marston Manthorpe, and Silvio Varon \\ Department of Biology, University of California, San Diego, La Jolla, California 92093
}

\begin{abstract}
The well-documented but little-understood failure of lengthy axonal regeneration after injury of the adult mammalian CNS may be caused by an insufficient availability of local growthpromoting factors. If so, identifying and supplying the missing factors may result in better central axonal regeneration. This hypothesis was tested in an adult rat CNS model in which peripheral nerve grafts were placed into a lesion cavity between the septum and hippocampal formation. Continuous infusion of nerve growth factor (NGF) into the dorsal hippocampal tissue dramatically enhanced and accelerated the regrowth and penetration of cholinergic axons into the hippocampal formation. Thus, NGF can overcome the apparent resistance of the hippocampal CNS tissue to cholinergic reinnervation.
\end{abstract}

In contrast to developing or peripheral nervous systems, the adult mammalian CNS fails to regenerate nerve fibers after injury. The results of many studies support the view that the capacity for axonal growth in the mature CNS is not irretrievably lost and that central axonal regeneration fails because of an inadequate tissue environment (Clemente, 1964; Varon, 1977). For example, neurons from various adult rat brain and spinal cord regions exhibit robust and lengthy axonal regeneration through peripheral nerve grafts, though rarely beyond them for significant distances (Aguayo, 1985). It remains to be seen whether the CNS tissue environment can be manipulated to overcome its apparent restrictiveness to axonal regrowth.

The septohippocampal cholinergic system of the rat provides a valuable model for the investigation of adult mammalian CNS regeneration. Cholinergic neurons from the medial septum and diagonal band project their axons through distinct pathways, the supracallosal striae and fimbria-fornix, which can be discretely transected. The transection results in a verifiably complete cholinergic denervation of their innervation territory, the hippocampal formation. This transection creates a defined lesion cavity for placement of septohippocampal regeneration "bridges." Cholinergic neurons in the adult septum and other basal forebrain regions (Whittemore and Seiger, 1987) are rcsponsive to nerve growth factor (NGF), a well-known neuronotrophic factor for PNS neurons, also involved in neurite out-

\footnotetext{
Received Mar. 13, 1990; revised May 4, 1990; accepted May 8, 1990.

We thank M. Spencer for producing the high-quality infusion devices and E. Hewitt, C. Murdock, and L. Thomas for skillful technical assistancc. This work was supported by NINCDS Grants NS-16349 and NS-25011 and by NSF Grants BNS-88-08285 and BNS-86-17034.

Correspondence should be addressed to Theo Hagg, Department of Biology, M-001, University of California at San Diego, La Jolla, CA 92093.

Copyright @ 1990 Society for Neuroscience $0270-6474 / 90 / 093087-06 \$ 03.00 / 0$
}

growth promotion in vitro and in vivo (Levi-Montalcini, 1987; Varon et al., 1988).

In a recent time-course study (Hagg et al., 1990a), cholinergic axons regenerating through nerve grafts placed between the disconnected septum and hippocampal formation showed a rapid but limited burst of growth into the hippocampal tissue. A potential involvement of endogenous NGF is suggested by findings that (1) relatively large amounts of NGF are produced by the cells within transected peripheral nerves, that is, similar to those used as septohippocampal grafts (Heumann et al., 1987; Taniuchi et al., 1988); and (2) the level of hippocampal NGF transiently increases upon septohippocampal denervation (Gasser et al., 1986; Korshing et al., 1986; Lärkfors et al., 1987). We have further shown (Hagg et al., 1990b) that a peripheral nerve deprived of its living cells loses it regeneration-promoting competence for cholinergic axons but reacquires it when pretreated with purified NGF. Such data encourage the speculation that (1) a local and transient availability of growth-promoting factors may be responsible for the initial rapid regeneration through the nerve graft and into the hippocampal tissue, (2) failure of sustained regeneration may primarily result from a lack of such factors, and (3) supplying the missing factors may promote further CNS regeneration. The present study was aimed at testing such a hypothesis. Here, we provide evidence that infusion of NGF into the denervated hippocampal formation dramatically promotes cholinergic fiber regrowth from a septohippocampal nerve graft into the hippocampal tissue.

\section{Materials and Methods}

All procedures have been described in detail elsewhere (Hagg et al., 1990a). Briefly, 200-gm adult female Sprague-Dawley rats were subjected to a complete bilateral aspirative fimbria-fornix transection. Either gelfoam ( $n=4$ rats, 8 brain sides) or $1.5-2-\mathrm{mm}$ pieces of fresh autologous sciatic nerve $(n=26)$ were placed bilaterally as bridges into the lesion gap between the septum and hippocampal formation as shown in Figure 1. Twenty of the nerve-implanted animals were unilaterally and continuously infused into the hippocampal formation with a carefully designed infusion device consisting of an Alzet 2002 mini-osmotic pump (coated with paraffin to lower its rate from 0.5 to $0.15-0.2 \mu \mathrm{l} / \mathrm{hr}$ ) connected to a thin 32-ga metal cannula by a vinyl-coil reservoir (Vahlsing et al., 1989). Starting immediately after nerve implantation, some of these rats were infused for 1 month into the dorsal hippocampal formation, at about $2 \mathrm{~mm}$ caudal to the graft/hippocampal interface with either control vehicle (artificial cerebrospinal fluid containing $1 \mathrm{mg} / \mathrm{ml}$ rat serum albumin; $n=5)$ or vehicle containing mouse $7 \mathrm{~S}$ NGF $(0.16$ $\mu \mathrm{g}$ or 1000 Trophic Units per day; prepared and assayed as described in Varon et al., 1972 and Manthorpe et al., 1986; $n=5$ ). Other rats ( $n$ $=5$ ) were infused with NGF into the ventral hippocampal formation, about $7 \mathrm{~mm}$ from the graft, also for 1 month starting immediately after nerve implantation. After 1 month, the infusion devices were removed, their patency tested, and the residual NGF in the line reservoir was assayed and found to contain at least $30 \%$ of its original biological activity. In yet another set of nerve-implanted rats $(n=5)$, a 3-day 
Figure 1. Schematic sagittal representation of rat brain and septohippocampal model used to evaluate cholinergic fiber regeneration. Sciatic nerve grafts $(G)$ were placed in a lesion gap between the septum $(S)$ and the hippocampal formation $(H)$. In sagittal sections, determinations were made of the number of AChE-positive fibers intersecting imaginary lines through the hippocampal end of the nerve graft $(N)$ and at 0.1 (0), 1,2, and $3 \mathrm{~mm}$ from the rostral tip of the hippocampal formation. Asterisk, position of dorsal hippocampal infusion; dot, ventral hippocampal infusion.

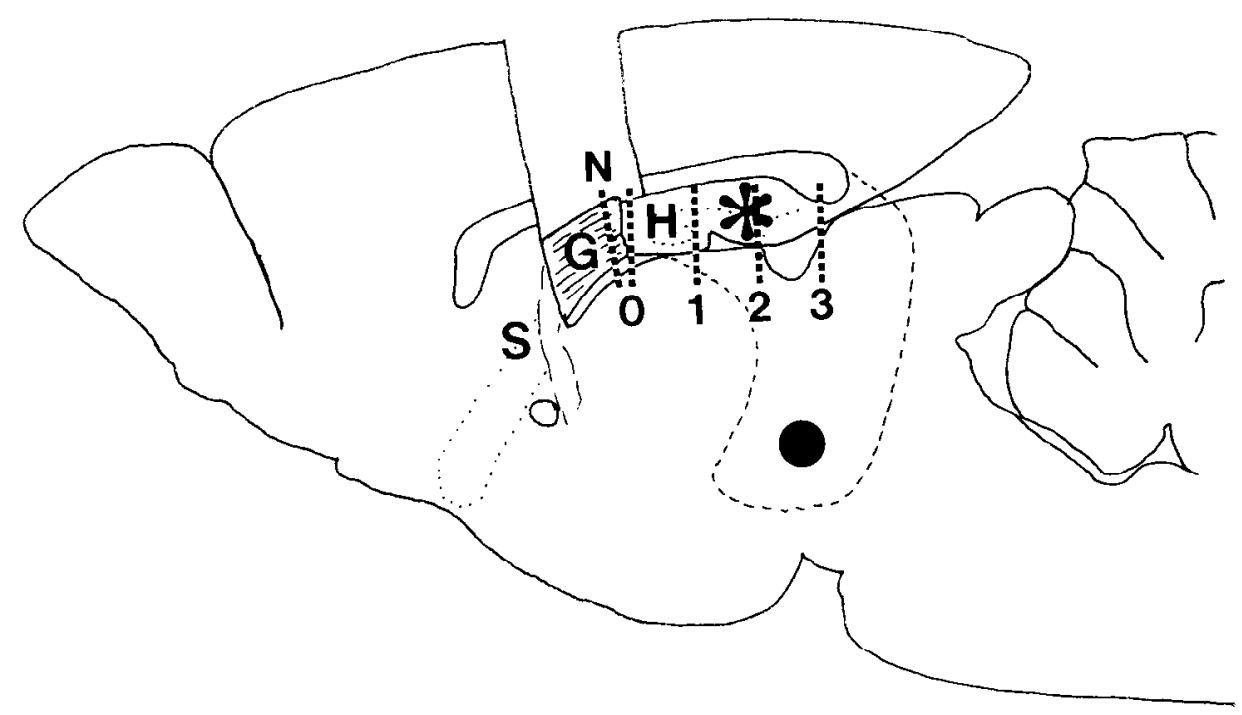

dorsal hippocampal infusion with vehicle $(n=2)$ or $\operatorname{NGF}(n=3)$ was started 1 month after nerve implantation. Six rats (12 sides) received nerve implants for 1 month without an infusion. One month after gelfoam- or nerve-implantation (or at the end of the infusion), all operated animals and 3 normal, unoperated animals were transcardially perfused with cold phosphate buffered saline and $4 \%$ paraformaldehyde, the brains were postfixed and cryoprotected with $30 \%$ sucrose, and $40-\mu \mathrm{m}$ sagittal sections were cut on a freezing microtome. One of every 12 sections was mounted on glass slides, dried overnight, and stained for $\Lambda \mathrm{ChE}$ (Hedreen et al., 1985) using Promethazine (0.2 mM, Sigma) as an inhibitor of nonspecific esterases.

Quantitative analyses of AChE-stained sagittal brain sections (480 $\mu \mathrm{m}$ apart) were carried out as described previously (Hagg et al., 1990a). In each section, we counted the number of AChE-positive fibers intersecting eye-piece grid lines placed perpendicular to the axis of the nerve graft or hippocampal formation at -0.2 (Fig. 1, N), 0.1 (Fig. 1, 0), 1, 2 , and $3 \mathrm{~mm}$ from the hippocampal rostral tip. In the nerve graft (Fig. $1, \mathrm{~N}$ line), cholinergic fiber structures had a tendency to form fascicles and were scored at $500 \times$ as thin (single fibers, $\leq 1 \mu \mathrm{m}$ ), medium, or thick ( $\geq 4 \mu \mathrm{m}$ ), in single sections containing the largest fiber mass in the graft. The total number of cholinergic axons in nerve-graft sections can be grossly estimated by speculating that the thin, medium, and thick structures contain 1,3 , and 5 axons, respectively, as judged from the diameter of the individual fibers and the number of fibers found to converge into and diverge from medium and thick fiber structures. This method may underestimate the total number of axons. In the dorsal hippocampal formation, on the other hand, individual regenerating fibers were clearly distinguishable, and the number of fiber intersections at each successive $1-\mathrm{mm}$ distance was directly determined in each section at $250 \times$. To determine the total number of fibers counted per brain side, fiber numbers at corresponding hippocampal distances of all AChEstained sections ( 1 of every 12 ) on one side of the brain were summed. A measure for the fastest-growing fibers or fiber front was derived by measuring the maximal distance at which 10 fibers (about $5 \%$ of normal) could be detected in a single section. The ventral hippocampal formation was excluded from all quantitative analyses because it contains some spared cholinergic fibers from the untransected ventral septohippocampal pathway (Gage et al., 1984). Moreover, there was always a substantial area with no AChE-positive fibers separating the regenerated fibers from the ventral hippocampal formation.

\section{Results}

In contrast to normal animals (Fig. $2 \mathrm{~A}$ ), 1 month after surgery, virtually no AChE-positive axons could be detected in the dorsal hippocampal formation of animals receiving only a gelfoam implant in the fimbria-fornix transection cavity (Fig. $2 B$ ). This confirmed that the lesions had caused complete hippocampal cholinergic denervation and that without intervention, no re- generation to the hippocampus had occurred. One month after sciatic nerve implantation, many regenerated $\mathrm{AChE}$-positive fibers had crossed through the nerve graft and entered the dorsal hippocampal formation, and infusion of vehicle alone during that month had no detectable effects (Fig. 2C). Nerve-grafted animals receiving a 1 -month NGF infusion into the dorsal hippocampal formation displayed a much greater density and penetration of cholinergic axons (Fig. 2D) than vehicle-treated rats. As illustrated in Figure 3, the 3-dimensional extent of cholinergic fiber reinnervation into the hippocampal formation seen in animals with a nerve bridge plus 1 month hippocampal NGF infusion was much greater than in ones with nerve grafts but no NGF infusion. With dorsal NGF infusion, cholinergic fibers had extended past the point of infusion.

In this study, we used a specially made infusion device that allows the continuous administration of substances into brain parenchyma (Vahlsing et al., 1989). Of 10 animals infused for 1 month in the dorsal hippocampal formation with this new device, 8 showed no tissue damage beyond the width of the cannula tract itself. In the other 2 animals, the diameter of the lesion was less than twice that of the cannula. Such minimal damage was far less than the invariably severe necrotic damage obtained with an earlier version of the infusion device that released pump-derived cytotoxins into the brain tissue.

Apposition and alignment of the nerve against the septum and hippocampal formation was somewhat variable, but this variability was grossly the same in all animal groups. Moreover, the numerical spread of values within individual groups was small enough to yield statistical significance $(p \leq 0.05)$ using the nonparametric Mann-Whitney $U$-test for the differences discussed in the text.

Dorsal hippocampal NGF infusion for 1 month had no apparent effect on the number of thin, medium, or thick fiber structures at the hippocampal end of the nerve graft (Table 1), particularly if one considers the lack of sensitivity of this particular quantification method. The hippocampal values of 1 -month vehicle-infused nerve-implanted animals were not significantly different from those found in noninfused animals (Table 2), suggesting that the infusion, per se, does not affect the regeneration of cholinergic axons into the hippocampal tissue. With a 1 -month dorsal NGF infusion, the number of fiber in- 

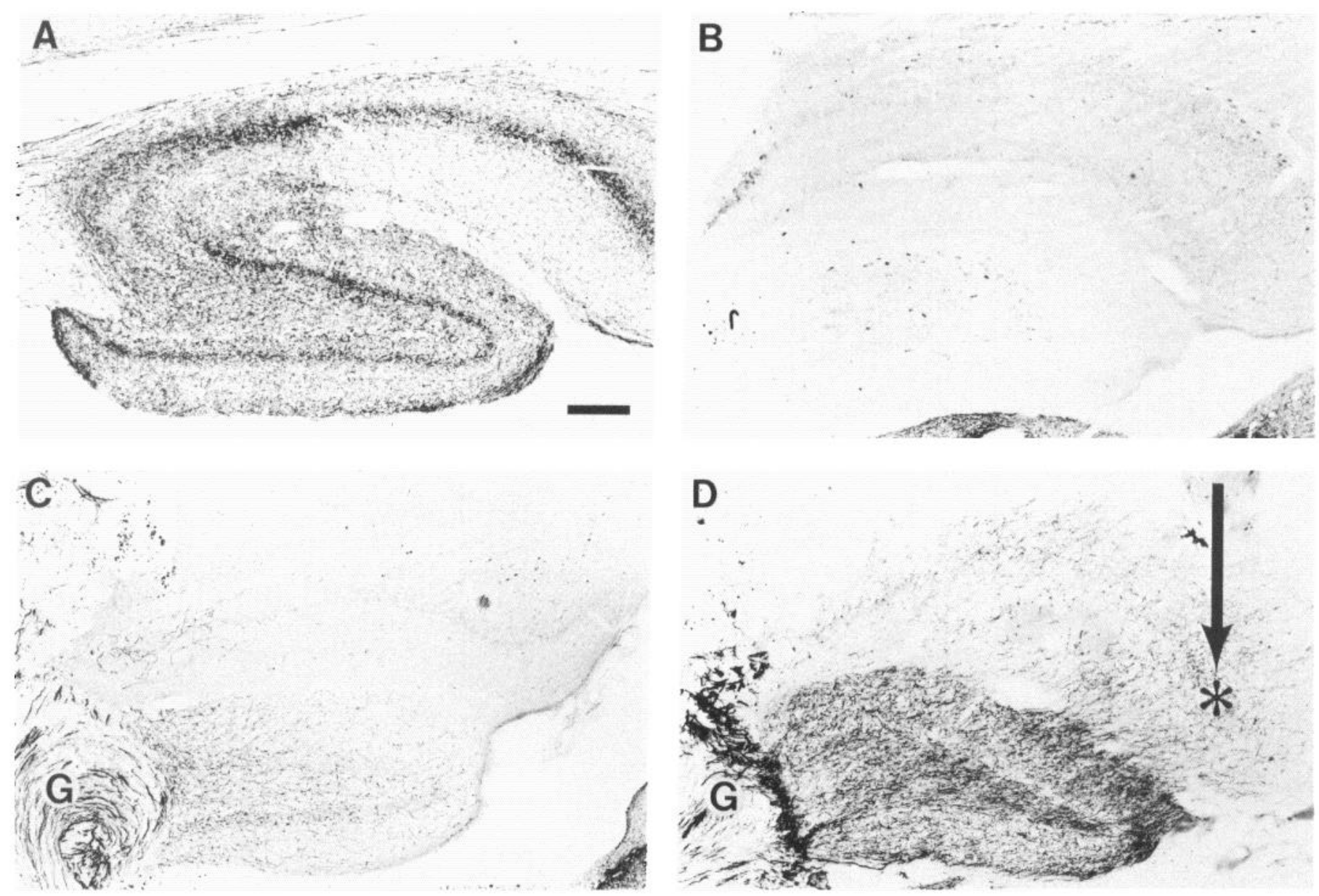

Figure 2. Intrahippocampal NGF promotes cholinergic axonal regeneration into the hippocampal formation. A, Sagittal section of a normal AChEstained hippocampal formation. Scale bar, $250 \mu \mathrm{m}$. B, One month after fimbria-fornix transection, the hippocampal formation of gelfoam-implanted animals showed no AChE-positive fibers. $C$, With a sciatic nerve graft $(G)$, many fibers had regrown into the dorsal hippocampal formation. $D$, NGF infusion for 1 month into the dorsal hippocampal formation, in addition to a nerve graft $(G)$, considerably increased hippocampal reinnervation by AChE-positive fibers. Asterisk, infusion site.

tersections at the entrance of the hippocampal formation $(0.1$ $\mathrm{mm}$ level, Table 2) was 3-4 times greater than with vehicle or nerve grafts alone $(p \leq 0.0005)$. The maximal number of fibers per single section (not shown) of these NGF-infused animals reached up to about $70 \%$ of that found in corresponding hippocampal regions $(0.1 \mathrm{~mm}, 1 \mathrm{~mm})$ of normal untransected animals $(150 \pm 9$ vs $212 \pm 7$ SEM fibers per single section, $n=$ 6 sides). With NGF infusion, there was also a much more extensive penetration into deeper hippocampal regions than in non-NGF infused animals, both in absolute total numbers and as percentages of the total number of fibers at the hippocampal entrance $(0.1 \mathrm{~mm})$. The maximal distance into the dorsal hippocampal formation at which 10 fibers (about $5 \%$ of normal) could be found in a single section, a measure for the fastest growing fibers (fiber front), was about $2.7 \mathrm{~mm}$ in 1-month dorsal-NGF-infused animals compared to only $1.4 \mathrm{~mm}$ in nerveimplanted animals without NGF or $0.2 \mathrm{~mm}$ in gelfoam-implanted control animals. In the contralateral hippocampal formation of animals with a 1-month unilateral dorsal hippocampal NGF infusion, the fiber numbers were lower than those

Table 1. Quantitative analyses of cholinergic axonal regeneration across the nerve bridge

\begin{tabular}{|c|c|c|c|c|c|}
\hline \multirow[b]{2}{*}{ Experimental group } & \multirow[b]{2}{*}{$n$} & \multicolumn{4}{|c|}{ Number of nerve fiber structures \pm SEM } \\
\hline & & Thin & Medium & Thick & Estimated total \\
\hline Nerve only & 12 & $49 \pm 4$ & $62 \pm 6$ & $6 \pm 1$ & $265 \pm 22$ \\
\hline Nerve and dorsal hippocampal vehicle & 5 & $34 \pm 3$ & $59 \pm 8$ & $6 \pm 2$ & $238 \pm 32$ \\
\hline Nerve and dorsal hippocampal NGF & 5 & $43 \pm 6$ & $80 \pm 6$ & $5 \pm 3$ & $333 \pm 41$ \\
\hline
\end{tabular}

Presented are the numbers of AChE-positive thin, medium, and thick fiber structures counted at the end of the nerve implant facing the hippocampal formation ( $\mathrm{N}$ line in Fig. 1). The total numbers of axons were estimated by assigning the values of 1,3 , and 5 axons to the thin, medium, and thick fibers, respectively. $n=$ number of individual brain sides. 

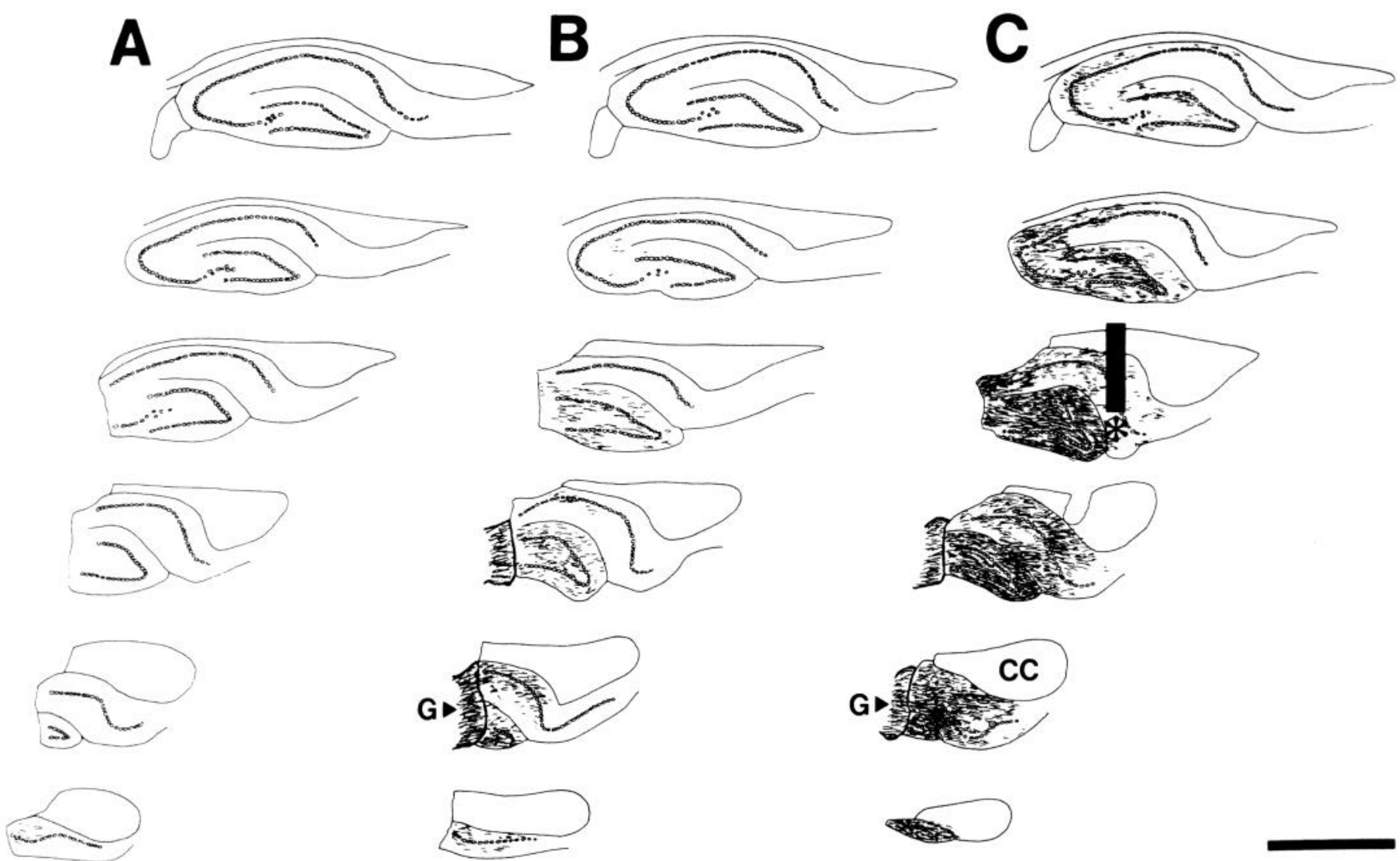

Figure 3. Extent of cholinergic hippocampal reinnervation 1 month after gelfoam $(A)$, nerve graft $(B)$, or nerve graft implantation plus a 1-month dorsal hippocampal NGF infusion $(C)$, as illustrated in drawings of 0.5 -mm-spaced sagittal sections through the hippocampal formation. A representative animal with fiber and distance values close to average was chosen for each experimental group. Camera lucida techniques were used to trace representative densities rather than individual cholinergic fibers. Scale bar, $2 \mathrm{~mm}$. CC, corpus callosum; G, graft; vertical bar and asterisk, infusion site.

found ipsilateral to the infusion but higher than those found in the vehicle-infused $(0.1 \mathrm{~mm}$, just below significance, $p \leq 0.1$; $1 \mathrm{~mm}, p \leq 0.05)$ or noninfused $(0.1 \mathrm{~mm}, p \leq 0.025 ; 1 \mathrm{~mm}, p$ $\leq 0.005$ ) hippocampal formations. Ventral hippocampal NGF infusions also induced increased cholinergic reinnervation in the ipsilateral dorsal hippocampal formation compared to vehicle- and noninfused $(0.1 \mathrm{~mm}, p \leq 0.005 ; 1 \mathrm{~mm}, p \leq 0.01)$ animals, though never to the extent achieved with dorsal NGF infusions.

To determine whether NGF merely induced an increase in AChE staining, a dorsal hippocampal NGF infusion was started 1 month after nerve implantation. After 3 days with such an NGF infusion, the number of AChE-positive hippocampal fibers was no greater than with a vehicle infusion over the same period (data not shown). These numbers were also not different from those in nerve-implanted animals receiving a 1-month vehicle infusion or no infusion at all.

\section{Discussion}

The results presented here demonstrate that infusion of NGF for 1 month into the hippocampal formation dramatically increases the extent of cholinergic hippocampal reinnervation. We have previously reported (Hagg et al., 1988, 1989a) that NGF can rapidly (1-3 d) upregulate the ChAT content, and thus the ChAT-mediated detectability, of axotomized (ChAT-negative) cholinergic medial septum neurons. Thus, in the present study,
NGF might merely have upregulated the marker enzyme AChE by which previously regenerated (but AChE-negative) axons would be made recognizable. A 3-day NGF-infusion into the dorsal hippocampal formation starting 1 month after nerve implantation, however, did not induce the appearance of an AChEpositive fiber plexus. Although the unlikely possibility that longer-term NGF infusion would only upregulate AChE cannot be ruled out, this suggests that the NGF-induced appearance of AChE-positive fibers in the hippocampal formation represents genuine axonal elongation into the receiving CNS territory.

The NGF-induced increase in the number of regrown cholinergic fibers in the hippocampal formation occurred without any apparent increase in fiber numbers in the nerve graft. Thus, NGF does not appear to promote regeneration into the hippocampal formation by recruiting more cholinergic neurons or by increasing the availability of more fibers at the distal nervegraft end. Furthermore, NGF infusion increased not only the number of fibers at the hippocampal entrance $(0.1 \mathrm{~mm}$ level), but also the proportion of the entering fibers that reached deeper regions (e.g., numbers at level $1 \mathrm{~mm}$ as a percentage of level $0.1 \mathrm{~mm}$ ). This suggests that NGF promotes regeneration by facilitating a better penetration of fibers into and throughout all regions of the hippocampal CNS tissue. Thus, NGF can change the apparently "restrictive" environment to make it more conducive to axonal penetration. It is of interest that NGF-producing fibroblast grafts have also recently been seen to induce 
Table 2. Quantitative analyses of cholinergic axonal regeneration in the dorsal hippocampal formation

\begin{tabular}{|c|c|c|c|c|c|c|}
\hline \multirow[b]{2}{*}{ Experimental group } & \multirow[b]{2}{*}{$n$} & \multicolumn{4}{|c|}{ Number of hippocampal fiber intersections \pm SEM } & \multirow{2}{*}{$\begin{array}{l}\text { Maximum } \\
\text { distance }(\mathrm{mm})\end{array}$} \\
\hline & & $0.1 \mathrm{~mm}$ & $1 \mathrm{~mm}$ & $2 \mathrm{~mm}$ & $3 \mathrm{~mm}$ & \\
\hline No nerve & 8 & $25 \pm 8^{* * * *}$ & $3 \pm 2^{* * * * *}$ & $0^{* *}$ & 0 & $0.2 \pm 0.1^{* * * * *}$ \\
\hline Nerve only & 12 & $137 \pm 19$ & $56 \pm 10$ & $3 \pm 1$ & 0 & $1.4 \pm 0.1$ \\
\hline Nerve and dorsal hippocampal vehicle & 5 & $120 \pm 29$ & $67 \pm 14$ & $5 \pm 4$ & 0 & $1.4 \pm 0.2$ \\
\hline $\begin{array}{l}\text { Nerve and dorsal hippocampal NGF } \\
\text { ipsilateral to infusion }\end{array}$ & 5 & $476 \pm 47^{* * * *}$ & $406 \pm 49^{* * * *}$ & $94 \pm 27^{* * * *}$ & $1 \pm 1$ & $2.7 \pm 0.2^{* * * *}$ \\
\hline $\begin{array}{l}\text { Nerve and dorsal hippocampal NGF } \\
\text { contralateral to infusion }\end{array}$ & 5 & $189 \pm 18^{*}$ & $99 \pm 13^{* *}$ & $6 \pm 2$ & 0 & $1.6 \pm 0.2$ \\
\hline Nerve and ventral hippocampal NGF & 5 & $273 \pm 59^{* *}$ & $136 \pm 32^{*}$ & $36 \pm 13^{* * *}$ & $3 \pm 3$ & $2.2 \pm 0.1^{* * *}$ \\
\hline
\end{tabular}

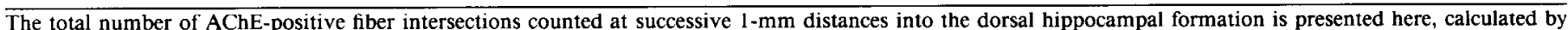

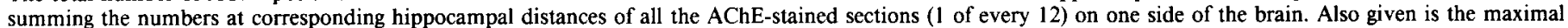

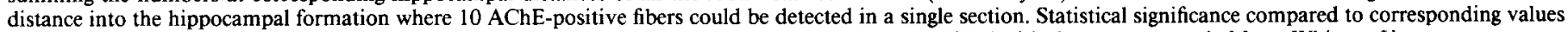
of the dorsal hippocampal vehicle-infused group (nerve and dorsal hippocampal vehicle) was determined with the nonparametric Mann-Whitney $U$-test.

$* p \leq 0.1$.

** $p \leq 0.05$

*** $p \leq 0.025$.

$* * * * p \leq 0.005$

$* * * * * p \leq 0.001$

cholinergic axonal growth into the denervated cortex from the adult rat host itself or from transplanted fetal brain tissue (Ernfors et al., 1989).

Regeneration of cholinergic fibers into the dorsal hippocampal formation was also promoted by infusion of NGF into the ventral hippocampal formation $7 \mathrm{~mm}$ away on the ipsilateral side and, to a lesser extent, by infusion of NGF into the dorsal hippocampal formation on the contralateral side of the brain. Thus, parenchymally infused NGF can diffuse through the brain tissue and/or the ventricular spaces and exert its promoting effects over such distances. Further experiments will be required to define optimal duration, dose, and locations of NGF administration that might allow full reinnervation of the hippocampal formation.

Treatment with NGF or other regeneration-promoting factors to facilitate the original and appropriate reinnervation in the adult CNS should meet at least the following requirements: (1) It should selectively recruit into the regenerative process the desired neuronal subsets. NGF may be selective for cholinergic neurons in the CNS (Whittemore and Seiger, 1987). (2) The treatment should affect only axotomized or damaged neurons. In the present study, only damaged cholinergic neurons appear to have responded, because ventral hippocampal NGF infusion did not induce obvious sprouting of the undamaged cholinergic ventral pathway. Similarly, intraseptal cholinergic sprouting was previously seen to occur in NGF-infused animals only in conjunction with a fimbria-fornix transection (Williams et al., 1986; Hagg et al., 1989b). In vitro, NGF has also been shown to promote axonal regeneration in cholinergic septal/basal forebrain neurons only after their axotomy (Schinstine and Cornbrooks, 1989). (3) An important question will be whether the NGF treatment would promote or at least respect a normal distribution pattern of reinnervation. Regenerating adult cholinergic axons have been shown to restore normal distribution patterns over a several-month period (Kromer et al., 1981; Hagg et al., 1990a). Such a pattern was not recognized in the present study, restricted to 1 month after implantation, where even the NGF-induced hippocampal fiber density reached only about
$70 \%$ of normal. Whether or not NGF would affect fiber distribution patterns may also depend on whether NGF promotes axonal regrowth through a tropic-attracting (Gundersen and Barrett, 1980) or a more general trophic action. The 2 modes of action have different implications for approaches to NGF therapy, because a tropic factor would attract fibers towards its point of infusion, allow no deeper CNS tissue penetration, and possibly disturb original innervation patterns, whereas a stimulatory/promoting factor might enhance regeneration without imposing or disturbing directional cues. (4) Synaptic reconnection to the "original" set of postsynaptic hippocampal neurons should be achievable under NGF treatment. This last requirement for NGF treatment is yet to be investigated.

laken together, the results of this study support the hypotheses that (1) the CNS tissue properties that oppose its penetration by regenerating adult axons arc not immutable, (2) failurc of central axonal regeneration may largely result from inadequate availability in CNS tissue of individual endogenous factors such as NGF, and (3) consequently, CNS axonal regeneration can be promoted by exogenous administration of such factors.

The central cholinergic systems may regenerate relatively well compared to other systems (Björklund and Stenevi, 1979). This may be due to the relative scarcity of myelination in this system (Björklund and Stenevi, 1979), especially in view of the recent reports (Caroni and Schwab, 1988; Schwab and Caroni, 1988; Schnell and Schwab, 1990) that CNS (optic nerve, corpus callosum, spinal cord) myelin-associated proteins inhibit neurite extension and regeneration both in vitro and in vivo. Nevertheless, the main concept emerging from the present septohippocampal system (promotion of cholinergic axonal regeneration by administration of a single neuronotropic factor, NGF) may be valid for all CNS neuronal systems, albeit with different types and relative amounts of such growth-promoting factors. Interestingly, optic nerve grafts, known to be negative/inhibitory terrains for axonal regeneration from several types of neurons, have recently been shown to provide a growth-promoting environment for neurosecretory hypothalamic neurons (Dellmann et al., 1989). 
In conclusion, administration into adult brain tissue of a single neuronotrophic factor, NGF, has a dramatic promoting effect on central cholinergic axonal regeneration. This indicates that CNS tissue has plastic properties amenable to manipulation by such individual factors, rather than being a structurally and permanently restricted environment. If these concepts are generalizable to other neuronal systems and other factors, they would provide a new level of understanding of the mechanisms that influence axonal regeneration in the adult mammalian CNS.

\section{References}

Aguayo AJ (1985) Axonal regeneration from injured neurons in the adult mammalian central nervous system. In: Synaptic plasticity (Cotman CW, ed), pp 457-484. New York: Guillford.

Björklund A, Stenevi U (1979) Regeneration of monoaminergic and cholinergic neurons in the mammalian central nervous system. Physiol Rev 59:62-100.

Caroni P, Schwab ME (1988) Two membrane protein fractions from rat myelin with inhibitory properties for neurite growth and fibroblast spreading. J Cell Biol 106:1281-1288.

Clemente CD (1964) Regeneration in the vertebrate central nervous system. Int Rev Neurobiol 6:257-301.

Dellmann H-D, Lue L-F, Bellin SI, Quassat M (1989) Magnocellular neurosecretory axon regeneration into rat intrahypothalamic optic nerve allografts. J Neurosci Res 24:163-168.

Ernfors P, Ebendal T, Olson L, Mouton P, Strömberg I, Persson H (1989) A cell line producing recombinant nerve growth factor evokes growth responses in intrinsic and grafted central cholinergic neurons. Proc Natl Acad Sci USA 86:4756-4760.

Gage FH, Björklund A, Stenevi U (1984) Cells of origin of the ventral cholinergic septohippocampal pathway undergoing compensatory collateral sprouting following fimbria-fornix transection. Neurosci Lett 44:211-216.

Gasser UE, Weskamp G, Otten U, Dravid AR (1986) Lesions of the septohippocampal pathway in rats induce elevation of nerve growth factor (NGF) content in the hippocampus and septum. Brain Res 367: 368-373.

Gundersen RW, Barrett JN (1980) Characterization of the turning response of dorsal root neurites toward nerve growth factor. J Cell Biol 87:546-554.

Hagg T, Manthorpe M, Vahlsing HL, Varon S (1988) Delayed treatment with nerve growth factor reverses the apparent loss of cholinergic neurons after acute brain damage. Exp Neurol 101:303-312.

Hagg T, Fass-Holmes B, Vahlsing HL, Manthorpe M, Conner JM, Varon $S$ (1989a) Nerve growth factor (NGF) reverses axotomyinduced decreases in choline acetyltransferase, NGF-receptor and size of medial septum cholinergic neurons. Brain Res 505:29-38.

Hagg T, Hagg F, Vahlsing HL, Manthorpe M, Varon S (1989b) Nerve growth factor effects on cholinergic neurons of neostriatum and nucleus accumbens in the adult rat. Neuroscience 30:95-103.

Hagg T, Vahlsing HL, Manthorpe M, Varon S (1990a) Septo-hippocampal cholinergic axonal regeneration through peripheral nerve bridges: quantification and temporal development. Exp Neurol (in press).

Hagg T, Gulati AK, Behzadian MA, Vahlsing HL, Varon S, Manthorpe
M (1990b) Nerve growth factor promotes CNS cholinergic axonal regeneration into acellular peripheral nerve grafts. Brain Res (in press).

Hedreen JC, Bacon SJ, Price DL (1985) A modified histochemical technique to visualize acetylcholinesterase-containing axons. J Histochem Cytochem 33:134-140.

Heumann R, Korshing S, Bandtlow C, Thoenen H (1987) Changes of nerve growth factor synthesis in nonneuronal cells in response to sciatic nerve transection. J Cell Biol 104:1623-1631.

Korshing S, Heuman R, Thoenen H, Hefti F (1986) Cholinergic denervation of the hippocampus by fimbria lesion leads to a transient accumulation of NGF without change in NGF mRNA content. Neurosci Lett 66:175-180.

Kromer LF, Björklund A, Stenevi U (1981) Regeneration of the septohippocampal pathways in adult rats is promoted by utilizing embryonic hippocampal implants as bridges. Brain Res 210:173-200.

Lärkfors L, Strömberg I, Ebendal T, Olson L (1987) Nerve growth factor protein level increases in the adult rat hippocampus after a specific cholinergic lesion. J Neurosci Res 18:525-531.

Levi-Montalcini R (1987) The nerve growth factor 35 years later. Science 237:1154-1162.

Manthorpe M, Fagnani R, Skaper SD, Varon S (1986) An automated colorimetric microassay for neuronotrophic factors. Dev Brain Res 25:191-198.

Schinstine M, Cornbrooks CJ (1989) Effects of nerve growth factor on the elongation of neurites from axotomized rat embryonic septalbasal forebrain neurons: an in vitro analysis. J Neurosci Res 23:371383.

Schnell L, Schwab ME (1990) Axonal regeneration in the rat spinal cord produced by an antibody against myelin-associated neurite growth inhibitors. Nature 343:269-272.

Schwab ME, Caroni P (1988) Oligodendrocytes and CNS myelin are non-permissive substrates for neurite growth and fibroblast spreading in vitro. J Neurosci 8:2381-2393.

Taniuchi M, Clark HB, Schweitzer JB, Johnson EM Jr (1988) Expression of nerve growth factor receptors by Schwann cells of axotomized peripheral nerves: ultrastructural location, suppression by axonal contact, and binding properties. J Neurosci 8:664-681.

Vahlsing HL, Varon S, Hagg T, Fass-Holmes B, Dekker A, Manley M, Manthorpe M (1989) An improved device for continuous intraventricular infusions prevents the introduction of pump-derived toxins and increases the effectiveness of NGF treatments. Exp Neurol 105: 233-243.

Varon S (1977) Neural growth and regeneration: a cellular perspective. Exp Neurol 54:1-6.

Varon S, Nomura J, Perez-Polo JR, Shooter EM (1972) The isolation and assay of the nerve growth factor proteins. In: Methods and techniques of neurosciences (Fried R, ed), pp 203-229. New York: Dekker.

Varon S, Manthorpe M, Davis GE, Williams LR, Skaper SD (1988) Growth factors. In: Functional recovery in neurological disease (Waxman SG, ed), pp 493-521. New York: Raven.

Whittemore SR, Seiger $\AA$ (1987) The expression, localization and functional significance of $\beta$-nerve growth factor in the central nervous system. Brain Res Rev 12:439-464.

Williams LR, Varon S, Peterson GM, Wictorin K, Fisher W, Björklund A, Gage FH (1986) Continuous infusion of nerve growth factor prevents forebrain neuronal death after fimbria-fornix transection. Proc Natl Acad Sci USA 83:9231-9235. 